Supplement of Nat. Hazards Earth Syst. Sci., 19, 1329-1346, 2019

https://doi.org/10.5194/nhess-19-1329-2019-supplement

(c) Author(s) 2019. This work is distributed under

the Creative Commons Attribution 4.0 License.

(c) (1)

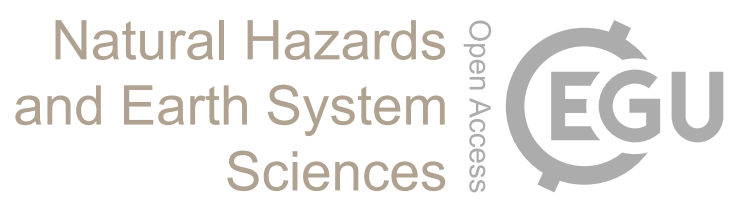

Supplement of

\title{
How awareness and confidence affect flood-risk precautionary behavior of Greek citizens: the role of perceptual and emotional mechanisms
}

Katerina Papagiannaki et al.

Correspondence to: Katerina Papagiannaki (katpap@noa.gr)

The copyright of individual parts of the supplement might differ from the CC BY 4.0 License. 


\section{The Online Questionnaire}

The specific web-address of the online post that announced the survey is http://www.meteo.gr/article_view.cfm?entryID=183. Below you can see the entire translated questionnaire. Note, however, that not all the questions have been used in this analysis. The type of the survey questions were closed-ended questions: rating scale (Likert-type scales and semantic differential scales), multiple choice questions, dichotomous and demographic questions. More details about the synthesis of the variables are provided in the article.

\section{Introduction}

Research on the preparedness of society in the event of floods.

The following questionnaire is an initiative of meteo.gr. It aims to gather evidence on the preparedness of citizens in flood events and the individual perception of flood risk.

Completing the questionnaire will not take more than 5 minutes. Your answers will be anonymous and confidential (limited use for scientific research purposes). To be taken into account in the survey, you need to answer all the questionnaire questions.

Thank you in advance for your active participation in this research, whose aim is to contribute to a deeper understanding of the causes of the ineffective defense of citizens against floods.

\section{Your personal experience}

Have you or your relatives experienced negative flash flood impact in the past? yes/no

How many were they?

Number

When was the most recent event?

Date

Fill the municipality and area where this event occurred.

Text

Evaluate the severity of the damage during this incident.

\section{5-point Likert scale}

Have you been informed in time of the flood risk in your area?

yes/no

Did you ever have to evacuate your home due to flood risk in the past?

yes/no

Have you received state compensation for flood damage in your property?

yes/no

Have you received compensation from private insurance for flood damage in your property?

yes/more than once/no

\section{Risk assessment}

How worried do you feel about the idea of a future flood?

5-point Likert scale

In the event of a future flood, how likely do you think any of the following may happen to you?

5-point Likert scale 
[Interruption of telecommunications, electrification]

[Transport Problems]

[Serious damage to your personal belongings (eg vehicles, outdoors / residential areas)]

[Destruction partial / total of your residence]

[Injury or loss of your intimates]

How concerned do you feel about the consequent impact in case of a flood event?

\section{5-point Likert scale}

[Interruption of telecommunications, electrification]

[Transport Problems]

[Serious damage to your personal belongings (eg vehicles, outdoors / residential areas)]

[Destruction partial / total of your residence]

[Injury or loss of your intimates]

Have you or any other family member taken any of the following measures to avoid negative flood-related impacts?

\section{Multiple choices}

[preventive drain cleaning, rain gutter control of your home]

[preventive pumps in the underground areas of your home, storage of a generator, sand bags]

[private insurance and/or home/vehicle insurance for natural disasters]

[attending seminars or searching for flood and precautionary information]

[informing family members about practical protection measures during and after a flood event]

[construction or other modifications to your home in order to prepare for a possible flood]

[none of the above, the state has taken appropriate protective measures in my area]

[none of the above are necessary]

To what extent do you intend to make private expenses to protect yourself against future floods?

5-point Likert scale

How adequate do you think the local authorities measures taken to strengthen your area against future heavy rainfall / floods are?

5-point Likert scale

Do you think you are well aware of the dangers of flooding in your area?

5-point Likert scale

How well do you know the measures the state has taken to protect your area from flooding? 


\section{5-point Likert scale}

With which of the following information tools have you been notified by local authorities about local risks?

multiple choices

[Maps of areas vulnerable to floods]

[Brochures]

[Seminars for informing the local community]

[Information signs]

[Local media posts (press, internet)]

[None]

How much do you think each of the following has contributed to the occurrence of floods in your area?

\section{5-point Likert scale}

[The urbanization of the environment (dense construction, paved streams, arbitrary dwellings)]

[The inability of the soil to absorb water due to fires, illegal logging]

[Problematic water management (rivers, lakes, canals)]

[Ineffective measures taken by the state]

[Climate change with more frequent and extreme weather phenomena]

How do you usually learn about the upcoming hazardous weather events?

Multiple choices

[Television]

[Radio]

[Social media (facebook, twitter ...)]

[News pages of the internet]

[Meteorological web pages]

[Applications on mobile phone / tablet]

[Newspapers]

[From relatives, friends]

[I'm not updating]

\section{Demographic characteristics}

Age number

Gender

female/male

Family size 
Professional status single choice

[Unemployed]

[Employee]

[Freelance]

[Retired]

[Other]

Housing single choice

[Homeownership]

[Tenancy]

Type of residence single choice

[Detached house]

[Semi-basement / basement apartment]

[1st floor apartment]

[Other]

Accommodation near water stream (river, stream, canal, lake) yes/no

Distance from nearest water flow (river, stream, canal, lake) single choice

[Less than $1 \mathrm{~km}$ ]

[More than $1 \mathrm{~km}$ ]

Type of settlement single choice

[cottage]

[village]

[small town]

[city]

Existence of objective risks (eg stay in a high risk area, frequent floods, old / vulnerable house, etc.) yes/no/maybe

Are you willing to participate in similar research in the future? If so, please provide contact details (email or address or phone) so we can contact you. 